\title{
Reducing Damage Due to Chemical Reactions in Concrete Exposed to Sodium Chloride: Quantification of a Deleterious Chemical Phase Change Formation
}

\author{
Fadi Althoey* and Yaghoob Farnam \\ Department of Civil, Architectural and Environmental Engineering, Drexel University, Philadelphia, PA 19131
}

\begin{abstract}
It has been shown that sodium chloride can react with the tricalcium aluminate $\left(\mathrm{C}_{3} \mathrm{~A}\right)$ and its hydrates, leading to a formation of a deleterious chemical phase change during thermal cycling. It is believed that this chemical phase change is implicated in the premature deterioration of concrete pavements in the cold regions. This work examines the potential formation of the deleterious chemical phase change in several cementitious pastes made using different types of portland cement and supplementary cementitious materials (SCMs). The amount of the chemical phase change was quantified using a low-temperature differential scanning calorimetry. The results indicated that the formation of the chemical phase change can be reduced by using cements with low $\mathrm{C}_{3} \mathrm{~A}$ content. The addition of SCMs showed different effects on the chemical phase change formation. Slag and Class F fly ash could reduce the amount of the chemical phase change due to only the dilution effect whereas silica fume could significantly reduce the amount of the chemical phase change due to the dilution effect as well as pozzolanic reactions. Adversely, the addition of Class $\mathrm{C}$ fly ash showed a negative effect through increasing the formation of the chemical phase change.
\end{abstract}

\section{Introduction}

The weather conditions in the cold-regions are particularly severe for concrete infrastructures due to the heavy use of deicing chemicals that are usually applied on the roads in order to maintain a normal traffic flow. These chemicals are in the form of chloride-based salts such as sodium chloride $(\mathrm{NaCl})$, calcium chloride $\left(\mathrm{CaCl}_{2}\right)$, and magnesium chloride $\left(\mathrm{MgCl}_{2}\right)$. The $\mathrm{NaCl}$ is by far the most widely used chemical due to its low cost and availability [1]. The detrimental effects of these chemicals on the concrete pavements are often manifested as mass change, expansion, and reduction on the dynamic modulus of elasticity [2-8]. The mechanisms of concrete deterioration in the presence of the deicing chemicals have been attributed to two main reasons; (i) classic freeze-thaw issues due to supersaturated concrete pores and (ii) deleterious chemical reactions between the deicing chemicals and the cementitious matrix [9-14]. The former mechanism can be resolved through utilizing air-entrained admixtures which can establish an adequate void system to resist ice expansion pressures $[10,11]$. The latter can be addressed through using proper supplementary cementitious materials (SCMs) as a partial replacement of ordinary portland cement (OPC) to improve the durability of concrete in the presence of deicing salts through dilution and/or pozzolanic reactions [15-21].

It has been shown in our previous work that $\mathrm{NaCl}$ can interact with the calcium aluminate phases, mainly the tri-calcium aluminate $\left(\mathrm{C}_{3} \mathrm{~A}\right)$ and its hydrates (e.g., monosulfoaluminate, $\mathrm{AF}_{\mathrm{m}}$ ), leading to a formation of a deleterious chemical phase change [8]. It is believed that this chemical phase formation is different from the calcium oxychloride and the magnesium oxychloride that formed when concrete is exposed to $\mathrm{CaCl}_{2}$ and $\mathrm{MgCl}_{2}[22,5]$. It has been shown that the formation of the chemical phase in the case of $\mathrm{NaCl}$ is temperature dependent, and it is destructive to concrete only if the concrete temperature cycles between $4^{\circ} \mathrm{C}$ and $10^{\circ} \mathrm{C}$ (i.e., above the freezing temperature of water) $[8,3,6]$. Figure 1a shows the phase diagram for hydrated cement paste containing $\mathrm{NaCl}$ solution. This phase diagram can be used to show the effects of temperatures and salt concentrations on the formation of the chemical phase change. The observed phase change can form at lower temperatures, but above freezing points of salt concentrations $\geq 12 \%$ by mass. It has been also shown that the amount of the chemical phase formations increases as the salt concentration increases, and it is strongly dependent on the chemistry of the cement as shown in Figure 1b where OPC Type V (OPC V) showed a reduction in the enthalpy of fusion associated with the chemical phase change formation in comparison to OPC Type I (OPC I).

The aim of this paper is to find cementitious mixtures that can be used in transportation industry to mitigate the potential damage due to chemical reactions in concrete exposed to $\mathrm{NaCl}$ deicing salts.

\footnotetext{
* Corresponding author: fma35@drexel.edu
} 

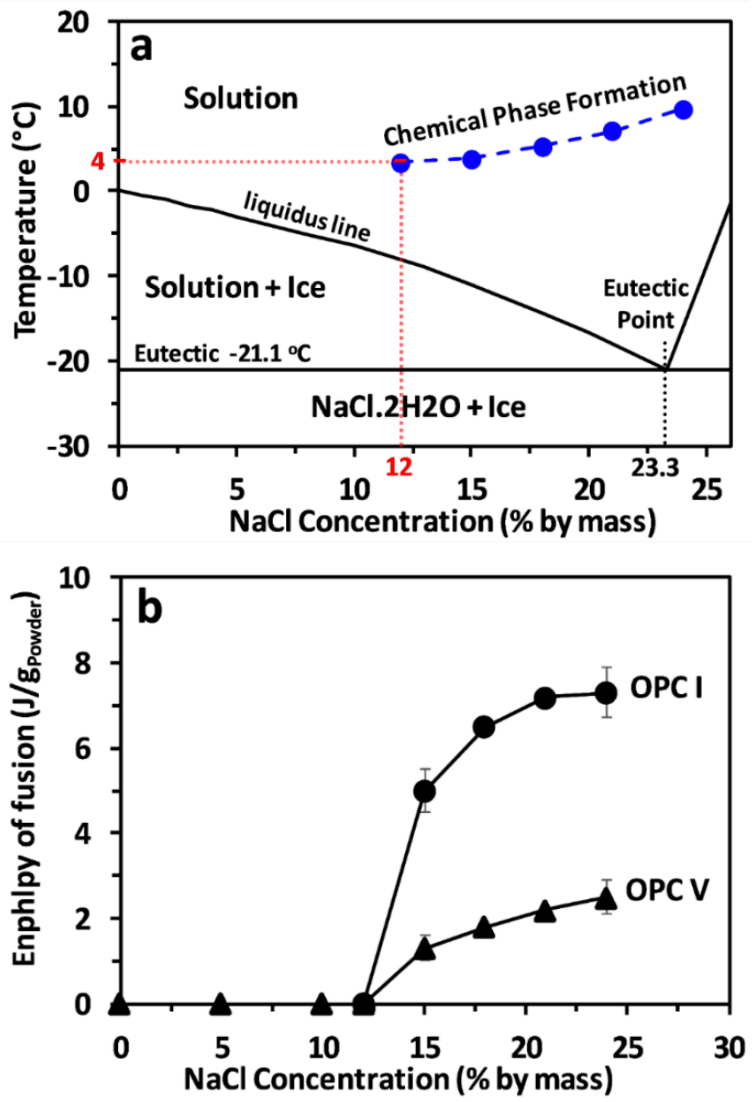

Fig. 1. (a) Hydrated cement- $\mathrm{NaCl}-\mathrm{H}_{2} \mathrm{O}$ phase diagram [6, 8]; (b) The heat released associated with the chemical phase formation of different hydrated cements containing different concentrations of $\mathrm{NaCl}$ solution [8].

\section{Experimental procedures}

\subsection{Materials and sample preparation}

An analytical-grade $\mathrm{NaCl}$ dehydrated was mixed with de-ionized water to prepare solutions with a concentration of $20 \%$ by mass. The use of this salt concentration results in the maximum chemical phase change formation that the cementitious materials can produce in the presence of $\mathrm{NaCl}$ solution as observed in our previous study (Figure 1b) [8]. Different types of OPC, including Type I, Type I/II and Type V, and SCMs including Class $\mathrm{C}$ fly ash, Class $\mathrm{F}$ fly ash, slag and silica fume were used in this study. The chemical compositions of the materials are listed in Table 1.

Cement pastes were made with water-to-cement ratio of 0.42 by mass. SCMs were tested with OPC I at different replacement levels by volume. Fly ashes and slag were used at $10,20,30,40$, and $60 \%$ replacement levels and the silica fume was used at 3, 5, 7, 10 and $15 \%$ replacement levels. The mixtures' proportions are listed in Table 2. The mixing was performed according to ASTM C305-14 using a standard mixer. No chemical admixtures were used in this study. After mixing, the pastes were cast into small plastic cylindrical molds with a diameter of $1 / 2$ in and a height of 1 in and sealed with a lid. The pastes were then cured at $23^{\circ} \mathrm{C}$ for 91 days. After curing, the hydrated pastes were ground using an agate mortar and pestle and sieved to obtain a powder with a fineness of $75-\mu \mathrm{m}$. The powder was then placed in a sealed container to minimize potential carbonation until the time of testing.

\subsection{Testing methods}

The testing procedures consisted of (1) mixing the ground powder with a $20 \% \mathrm{NaCl}$ solution and (2) exposing the blend to a cooling and heating cycle using a low-temperature differential scanning calorimetry (LTDSC). In this study, approximately $10 \mathrm{mg}$ of powder sample was mixed with approximately $10 \mathrm{mg}$ of $\mathrm{NaCl}$ solution to have a powder to solution mass ratio of 1 . The mixing was done in high-volume stainless-steel pans and then sealed with a hermetic lid. The sample was then placed in the LT-DSC and the following temperature cycle was applied: equilibrating at $25^{\circ} \mathrm{C}$; cooling to $90^{\circ} \mathrm{C}$ at $2^{\circ} \mathrm{C} / \mathrm{min}$; isothermal at $-90^{\circ} \mathrm{C}$ for $5 \mathrm{~min}$; heating to $30^{\circ} \mathrm{C}$ with $1^{\circ} \mathrm{C} / \mathrm{min}$. It should be mentioned herein that heating/cooling rates were selected to provide a reasonable quantification of the chemical phase change for the purpose of general comparison between different mixtures although other heating/cooling rates can be used for this testing method [23].

\subsection{Heat flow response and analysis}

The formation of the chemical phase change in hydrated pastes exposed to $\mathrm{NaCl}$ solution was identified by observing the LT-DSC heat flow vs temperature curve during the heating cycle. The heat flow curve as a function of temperature can be used to identify possible chemical phases present in the system that undergo phase changes (liquid to solid or vice versa). Figure 2 shows the typical LT-DSC curve during the heating cycle of a cementitious sample exposed to $20 \% \mathrm{NaCl}$ solution. Three distinguished endothermic peaks were observed, which correspond to; (a) the eutectic $\mathrm{NaCl}$ melting (at $-21.1^{\circ} \mathrm{C}$ ), (b) the ice melting (at $-12^{\circ} \mathrm{C}$ for $20 \% \mathrm{NaCl}$ solution) and (c) an additional peak observed at a temperature above $0^{\circ} \mathrm{C}$ associated with the formation of the deleterious chemical phase change. The area under each peak can be integrated with respect to time, resulting in the absorbed heat during melting (enthalpy of fusion) associated with each phase transformation. The enthalpy of fusion associated with the chemical phase change was estimated by measuring the magnitude of its heat absorbed during the melting from the cumulative heat curve, that is, the vertical distance along $y$-axis between the inflection points labeled as (1) and (2) in Figure 2. The enthalpy of fusion is a characteristic property of a material, which can be used as an indication of its amount [24]. In this study, therefore, the enthalpy of fusion was used to be representative of the amount of the chemical phase change being formed. 
Table 1. Chemical composition of cementitious materials (in percent by mass).

\begin{tabular}{|c|c|c|c|c|c|c|c|c|c|c|c|}
\hline ID & Type & Source & $\mathbf{S i O}_{\mathbf{2}}$ & $\mathbf{A l}_{\mathbf{2}} \mathbf{O}_{\mathbf{3}}$ & $\mathbf{F e}_{\mathbf{2}} \mathbf{O}_{\mathbf{3}}$ & $\mathbf{C a O}$ & $\mathbf{S O}_{\mathbf{3}}$ & $\mathbf{C 3 S}$ & $\mathbf{C 2 S}$ & $\mathbf{C 3 A}$ & $\mathbf{C 4 A F}$ \\
\hline C1 & OPC I & Nazareth, PA & 19.2 & 5.4 & 2.2 & 62.6 & 4.0 & 58.0 & 11.0 & 10.5 & 7.0 \\
\hline C2 & OPC I/II & - & 20.2 & 4.8 & 3.4 & 64.0 & 2.7 & 62.2 & 10.98 & 6.96 & 9.0 \\
\hline C3 & OPC V & - & 21.3 & 2.5 & 4.2 & 63.2 & 2.8 & 64.0 & 13.0 & 0.0 & 13.0 \\
\hline C-FA1 & Class C Fly Ash & Louisville, KY & 34.3 & 21.4 & 5.8 & 26.7 & 1.9 & - & - & - & - \\
\hline C-FA2 & Class C Fly Ash & Harrisburg, PA & 42.4 & 19.4 & 5.5 & 21.5 & 3.2 & - & - & - & - \\
\hline F-FA1 & Class F Fly Ash & Louisville, KY & 46.2 & 22.5 & 17.8 & 4.4 & 1.10 & - & - & - & - \\
\hline SC & Slag Cement & Pittsburgh, PA & 36.18 & 11.2 & 0.5 & 35.49 & 0.3 & - & - & - & - \\
\hline SF & Silica fume & Lyndhurst, NJ & 95.6 & 0.25 & 0.62 & 0.43 & 32 & - & - & - & - \\
\hline
\end{tabular}

Table 2. Testing matrix and mixtures proportions (in grams).

\begin{tabular}{|c|c|c|c|c|c|c|c|}
\hline Mix No. & ID & Cement & Water & C-fly ash & F-fly Ash & Silica Fume & Slag \\
\hline Mix 1 & C1 & 768 & 323 & - & - & - & - \\
\hline Mix 2 & C2 & 768 & 323 & - & - & - & - \\
\hline Mix 3 & C3 & 768 & 323 & - & - & - & - \\
\hline Mix 4 & $10 \%$ C-FA1 & 696 & 321 & 67 & - & - & - \\
\hline Mix 5 & $20 \%$ C-FA1 & 624 & 319 & 135 & - & - & - \\
\hline Mix 6 & $30 \%$ C-FA1 & 550 & 317 & 204 & - & - & - \\
\hline Mix 7 & $40 \%$ C-FA1 & 475 & 315 & 274 & - & - & - \\
\hline Mix 8 & $60 \%$ C-FA1 & 322 & 311 & 417 & - & - & - \\
\hline Mix 9 & $10 \%$ C-FA2 & 696 & 321 & 67 & - & - & - \\
\hline Mix 10 & $20 \%$ C-FA2 & 624 & 319 & 135 & - & - & - \\
\hline Mix 11 & $30 \%$ C-FA2 & 550 & 317 & 204 & - & - & - \\
\hline Mix 12 & $40 \%$ C-FA2 & 475 & 315 & 274 & - & - & - \\
\hline Mix 13 & $60 \%$ C-FA2 & 322 & 311 & 417 & - & - & - \\
\hline Mix 14 & $10 \%$ F-FA & 698 & 320 & - & 63 & - & - \\
\hline Mix 15 & $20 \%$ F-FA & 628 & 317 & - & 127 & - & - \\
\hline Mix 16 & $30 \%$ F-FA & 556 & 314 & - & 193 & - & - \\
\hline Mix 17 & $40 \%$ F-FA & 482 & 311 & - & 260 & - & - \\
\hline Mix 18 & $60 \%$ F-FA & 328 & 305 & - & 399 & - & - \\
\hline Mix 19 & $10 \%$ SC & 695 & 321 & - & - & - & 70 \\
\hline Mix 20 & $20 \%$ SC & 620 & 320 & - & - & - & 141 \\
\hline Mix 21 & $30 \%$ SC & 546 & 319 & - & - & - & 213 \\
\hline Mix 22 & $40 \%$ SC & 470 & 317 & - & - & - & 286 \\
\hline Mix 23 & $60 \%$ SC & 317 & 315 & - & - & - & 433 \\
\hline Mix 24 & $3 \%$ SF & 748 & 321 & - & - & 17 & - \\
\hline Mix 25 & $5 \%$ SF & 735 & 320 & - & - & 28 & - \\
\hline Mix 26 & $7 \%$ SF & 722 & 320 & - & - & 39 & - \\
\hline Mix 27 & $10 \%$ SF & 702 & 318 & - & - & 56 & - \\
\hline Mix 28 & $15 \%$ SF & 667 & 316 & - & - & 85 & - \\
\hline
\end{tabular}

Figure 3 shows the quantified enthalpy of fusion

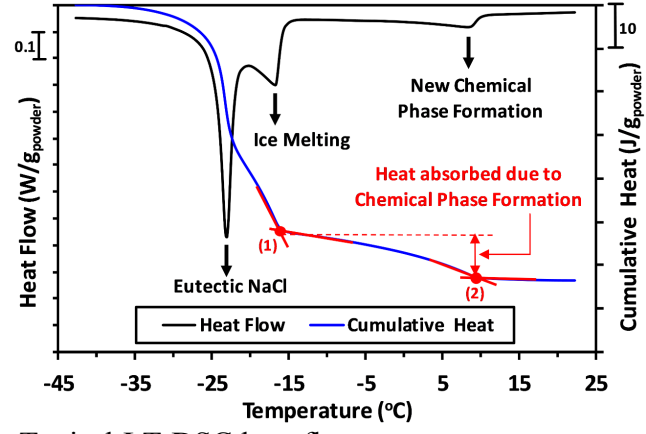

Fig. 2. Typical LT-DSC heat flow vs temperature curve during heating cycle of a cementitious sample exposed to $20 \% \mathrm{NaCl}$ solution along with the integration of the heat flow (cumulative heat) as a function of temperature.

\section{Results and discussion}

associated with the deleterious chemical phase change for all cementitious mixtures examined in this study. The standard deviation of the enthalpy of fusion of two replicated samples was rarely greater than 0.2 .

\subsection{Comparison of OPC mixtures}

The deleterious chemical phase change in pastes made with OPC I, OPC I/II and OPC V, labeled as C1, C2 and $\mathrm{C} 3$ respectively in Figure 3, were calculated as 8.87, 6.25 , and $2.38 \mathrm{~J} / \mathrm{g}_{\text {powder }}$ respectively. It was noted that different types of cement show considerable differences in the amount of the chemical phase change. OPC I sample (C1) shows the highest amount of the chemical phase change whereas OPC V sample (C3) shows the lowest. This implies that the formation of the chemical phase change is highly dependent on the cement chemistry (OPC $\mathrm{V}$ has typically low $\mathrm{C}_{3} \mathrm{~A}$ content according to ASTM C150-07, see Table 1). 


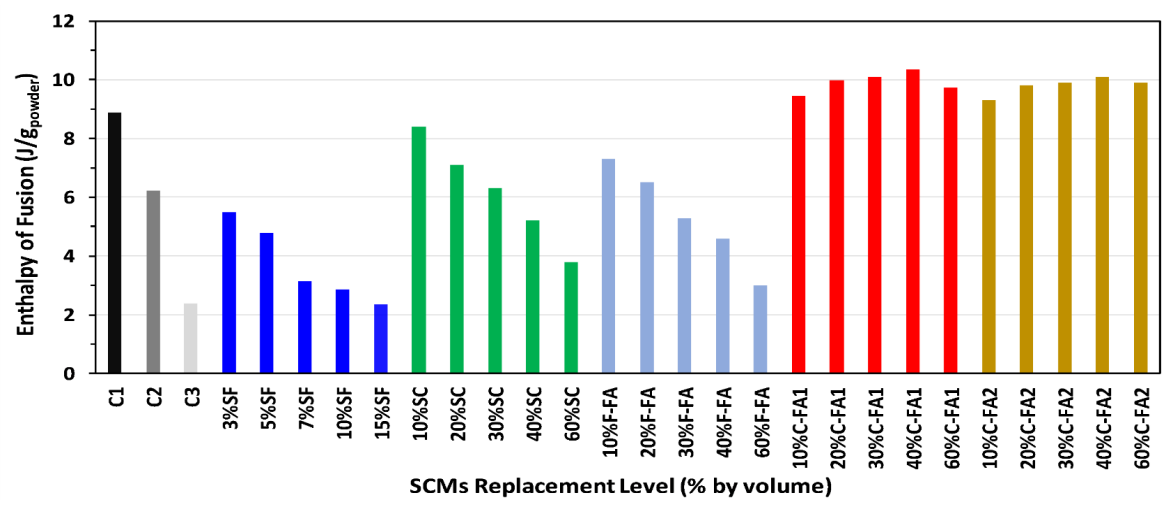

Fig. 3. Enthalpy of fusion associated with the deleterious chemical phase change for different cementitious pastes exposed to $20 \%$ $\mathrm{NaCl}$ solution.

Figure 4 indicates that there is a strong correlation between the amounts of the chemical phase change and the $\mathrm{C}_{3} \mathrm{~A}$ present in the cement, suggesting that the $\mathrm{C}_{3} \mathrm{~A}$ content plays a major role in the formation of chemical phase change which is in accordance with our previous study [8]. It can be concluded herein that one approach to minimize the formation of the deleterious chemical phase change, and the associated damage in concrete exposed to $\mathrm{NaCl}$ solution, may be to use cements with low $\mathrm{C}_{3} \mathrm{~A}$ content.

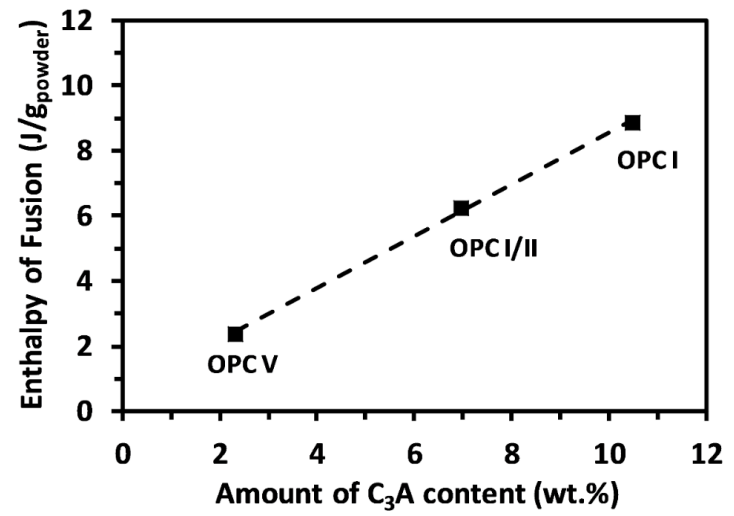

Fig. 4. The enthalpy of fusion associated with the formation of the deleterious chemical phase change for different OPC pastes exposed to $20 \% \mathrm{NaCl}$ solution.

\subsection{The role of SCMs}

It is expected that the addition of SCMs can improve the chemical stability of the cement through the dilution effect and/or pozzolanic reactions [19]. The use of SCMs as a partial replacement of the cement can reduce the amount of cement being used through the dilution effect. Moreover, SCMs can also alter the cement hydration process through pozzolanic activities. These factors can significantly affect the formation of the deleterious chemical phase change.

\subsection{Slag}

Figure 5a shows the effectiveness of slag additions on the formation of the chemical phase change. It indicates that as the amount of the slag increases in the binder, the amount of the chemical phase change linearly decreases. This reduction was mainly due to the dilution of cement by slag addition. The predicted dilution effect of slag was calculated as $0.0845 \mathrm{~J} / \mathrm{g}_{\text {powder }}$ for every volumepercentage of slag up to a replacement level of $60 \%$ (i.e., a $60 \%$ volume-replacement of slag can reduce the chemical phase formation up to approximately $60 \%$ ). This suggests that the slag contribution in reducing the chemical phase change amount is only due to the dilution effect.

\subsection{Silica fume}

Figure $5 \mathrm{~b}$ indicates the beneficial effects of silica fume additions on the formation of the chemical phase change. It shows that as the amount of the silica fume increases in the binder, the amount of the chemical phase change significantly decreases. This reduction exceeds the expected dilution effect, which implies that the benefit of the silica fume addition is pozzolanic activities in addition to the dilution effect. A $15 \%$ replacement of the cement with silica fume can reduce the amount of the chemical phase formation up to $74 \%$. It has been reported that the silica fume can alter the cement hydration process through accelerating the hydration of $\mathrm{C}_{3} \mathrm{~A}$ during the initial stages of the hydration process [25-27]. This can help in minimizing the amount of unreacted $\mathrm{C}_{3} \mathrm{~A}$ at later stages of the hydration, thereby making the concrete matrix less reactive in the presence of $\mathrm{NaCl}$ deicing salts.

\subsection{Class F fly ash}

Figure 5c shows the effect of Class $\mathrm{F}$ fly ash additions on the formation of the chemical phase change. It was noticed that as the amount of Class F fly ash increases in the binder, the amount of the chemical phase change linearly decreases. This reduction slightly exceeds the expected dilution effect, suggesting there might be slight pozzolanic benefits from Class $\mathrm{F}$ fly ash additions. The reduction on the chemical phase change due to the Class $\mathrm{F}$ fly ash was calculated as $0.0978 \mathrm{~J} / \mathrm{g}_{\text {powder }}$ for every volume-percentage of Class $\mathrm{F}$ fly ash up to a replacement level of $60 \%$. A high-volume class $\mathrm{F}$ fly ash replacement (up to $60 \%$ by volume) can reduce the chemical phase change up to $66 \%$. It seems that the 
effect of Class F fly ash on the chemical phase change is similar to the effect of slag, with the Class F fly ash being slightly more efficient.

\subsection{Class C fly ash}

Figure 5d shows the replacement effects of two Class C fly ashes manufactured at different locations in the US (see Table 1) on the formation of the chemical phase change. It was noticed that Class $\mathrm{C}$ fly ash has an adverse effect on the formation of chemical phase change in comparison with other SCMs used in this study. As the amount of Class $\mathrm{C}$ fly ash in the mixture increases, the amount of the chemical phase change increases. A similar behavior was observed for both Class $\mathrm{C}$ fly ashes used in this study. It has been reported that the Class $\mathrm{C}$ fly ash contains $\mathrm{C}_{3} \mathrm{~A}$ due to the high proportions of lime and alumina present [27-32]. Therefore, the addition of Class $\mathrm{C}$ fly ash may increase the $\mathrm{C}_{3} \mathrm{~A}$ content in the cement. This can make the concrete more reactive in the presence of $\mathrm{NaCl}$ deicing salts, and perhaps more susceptible to scaling as observed in several studies [33-37].
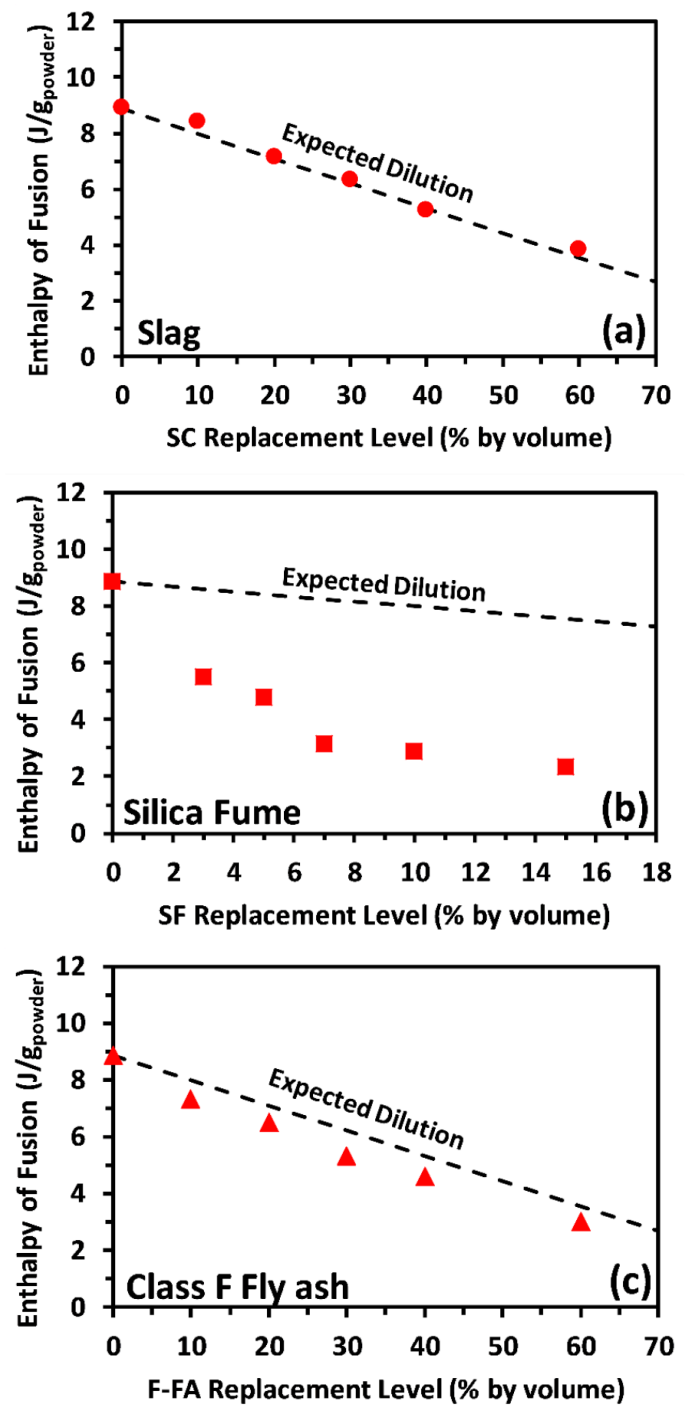

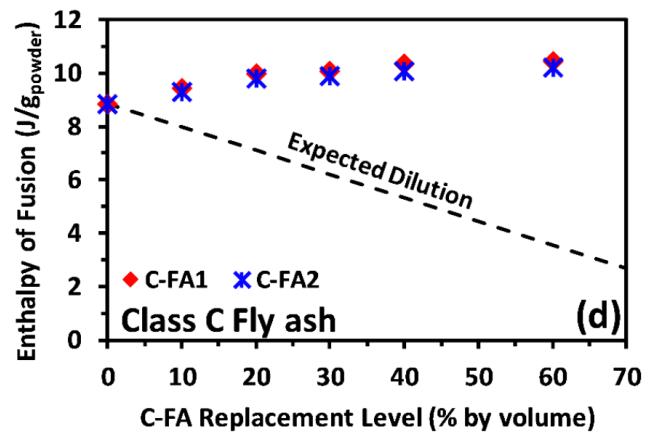

Fig. 3. Influence of SCMs additions on the formation of the deleterious chemical phase change: (a) slag cement; (b) silica fume; (c) Class F fly ash; and (d) Class C fly ash. Expected dilution line represents the potential reduction in the deleterious chemical phase due to only the dilution of cement by SCMs replacement.

\section{Conclusion}

This paper discusses potential approaches to mitigate damage due to chemical reactions in concrete exposed to $\mathrm{NaCl}$ salts. The $\mathrm{NaCl}$ can interact with tri-calcium aluminate $\left(\mathrm{C}_{3} \mathrm{~A}\right)$ and its hydrates in the cementitious matrix, leading to a formation of a deleterious chemical phase change during thermal cycling. The mitigation approaches focused on the use of different types of ordinary portland cement (OPC) as well as the potential to use supplementary cementitious materials (SCMs) as a partial replacement of the cement to improve the chemical stability of the concrete matrix in the presence of $\mathrm{NaCl}$, thereby minimizing the formation of the deleterious chemical phase change. The results showed that the formation of the deleterious chemical phase change is significantly sensitive to the chemistry of the cement and the type of the SCMs being used. The mixtures made using OPC I (high- $\mathrm{C}_{3} \mathrm{~A}$ cement) showed the highest amount of the chemical phase change whereas mixtures made using OPC $\mathrm{V}$ (low- $\mathrm{C}_{3} \mathrm{~A}$ cement) showed the lowest amount. A linear correlation between the chemical phase change and the $\mathrm{C}_{3} \mathrm{~A}$ amounts was observed: as the $\mathrm{C}_{3} \mathrm{~A}$ amount decreased, the chemical phase change amount decreased. The effect of SCMs additions as a partial replacement of the cement on the formation of the chemical phase change was found to be dependent on the type of SCMs. For mixtures containing slag or Class F fly ash, the reduction in the amount of the chemical phase change was only due to the dilution effect. The dilution effect due to slag or Class F fly ash additions was respectively estimated as $0.0845 \mathrm{~J} / \mathrm{g}_{\text {powder }}$ and $0.0978 \mathrm{~J} / \mathrm{g}_{\text {powder }}$ for every volume-percentage up to the replacement level of $60 \%$. For mixtures containing silica fume, the reduction in the amount of the chemical phase change was found to be due to both pozzolanic activities and the dilution effect. A $15 \%$ volume replacement of the cement with silica fume corresponded to a $74 \%$ reduction in the chemical phase change amount. Controversially, the use of Class C fly ash showed an increase in the chemical phase change amount. An examination of different Class C fly ashes obtained from different locations in the US showed 
similar behavior. This implied that the addition of Class $\mathrm{C}$ fly ash as a partial replacement of the cement may have a negative effect on the concrete durability in the presence of $\mathrm{NaCl}$ deicing salts.

The work was conducted in the Advanced and Sustainable Infrastructure Materials (ASIM) laboratory at Drexel University. The authors gratefully acknowledge Drexel University for the financial support provided through 2018 Faculty Summer Research Award which has made this work possible. The authors also gratefully thank Charah Solutions, CEMEX, and Sika Corporation for providing the materials used in this study. Any opinions discussed in this paper are those of the authors.

\section{References}

1. TRB. (2007). Guidelines for the Selection of Snow and Ice Control Materials to Mitigate Environmental Impacts. Washington, D.C.: NCHRP Report 577. https://doi.org/10.17226/23178.

2. Xianming, S., Fay, L., Peterson, M.M., and Yang, Z. (2010). Freeze-thaw Damage and Chemical Change of a Portland Cement Concrete in the Presence of Diluted Deicers. Materials and Structures. 43(7). Springer Netherlands, 933-946. https://doi.org/10.1617/s11527-009-9557-0.

3. Chunyu, Q., Suraneni, P., and Weiss, J. (2018). Damage in Cement Pastes Exposed to $\mathrm{NaCl}$ Solutions. Construction and Building Materials. https://doi.org/10.1016/j.conbuildmat.2018.03.123.

4. Marchand, J., Sellevold, E.J., and Pigeon, M. (1994). The Deicer Salt Scaling Deterioration of Concrete An Overview. In Third International Conference on Durability of Concrete, edited by V. M. Malhotra, 146. Nice, France.

5. Farnam, Y., Wiese, A., Bentz, D., Davis, J., and Weiss, J. (2015). Damage Development in Cementitious Materials Exposed to Magnesium Chloride Deicing Salt. Construction and Building Materials 93:384-92. https://doi.org/10.1016/j.conbuildmat.2015.06.004.

6. Farnam, Y., Bentz, D., Hampton, A., and Weiss, J.. (2014). Acoustic Emission and Low Temperature Calorimetry Study of Freeze and Thaw Behavior in Cementitious Materials Exposed to $\mathrm{NaCl}$ Salt. Transportation Research Board Record (Accepted), $1-18$.

7. Lawrence, S., Peterson, K., Touton, S., Van Dam, T., and Johnston, D. (2006). Petrographic Evidence of Calcium Oxychloride Formation in Mortars Exposed to Magnesium Chloride Solution. Cement and Concrete Research $36 \quad$ (8):1533-41. https://doi.org/10.1016/j.cemconres.2006.05.022.

8. Althoey, F., Wisner, B., Kontsos, A., and Farnam, Y. (2018). Cementitious Materials Exposed to High Concentration of Sodium Chloride Solution: Formation of a Deleterious Chemical Phase Change. Construction and Building Materials 167. Elsevier Ltd:543-52.

https://doi.org/10.1016/j.conbuildmat.2018.02.066.

9. Shi, X., Fay, L., Peterson, M.M., Berry, M., and
Mooney, M. (2011). A FESEM/EDX Investigation into How Continuous Deicer Exposure Affects the Chemistry of Portland Cement Concrete. Construction and Building Materials. 25(2):957-66. https://doi.org/10.1016/j.conbuildmat.2010.06.086.

10. Harris, D., Farnam, Y., Spragg, R., Imbrock, P., and Weiss, J. (2015). Early Detection of Joint Distress in Portland Cement Concrete Pavements. Purdue University. https://doi.org/10.5703/1288284315531.

11. Jones, W., Imbrock, P., Farnam, Y., Sprio, J., Villani, C., Olek, J., and Weiss, W.J. (2013). An Overview of Joint Deterioration in Concrete Pavement: Mechanisms, Solution Properties, and Sealers. JTRP Affiliated https://doi.org/10.5703/1288284315339.

12. Farnam, Y., Todak, H., Spragg, R., and Weiss, J. (2015). Electrical Response of Mortar with Different Degrees of Saturation and Deicing Salt Solutions during Freezing and Thawing. Cement \& Concrete Composites 59 (March):49-59. https://doi.org/10.1016/j.cemconcomp.2015.03.003.

13. Sutter, L., Peterson, K., Julio-Betancourt, G., Hooton, D., Dam, T., and Smith, K. (2008). The Deleterious Chemical Effects of Concentrated Deicing Solutions on Portland Cement Concrete. South Dakota Department of Transportation Office of Research 5 (April). Houghton, MI:216. https://doi.org/Final Report SD2002-01-F.

14. Peterson, K., Julio-Betancourt, G., Sutter, L., Hooton, D., and Johnston, D. (2013). Observations of Chloride Ingress and Calcium Oxychloride Formation in Laboratory Concrete and Mortar at $5 \mathrm{C}$. Cement and Concrete Research. 45(1):79-90. https://doi.org/10.1016/j.cemconres.2013.01.001.

15. Suraneni, P., Azad, V., Burkan, I., and Weiss, J. (2017). Use of Fly Ash to Minimize Deicing Salt Damage in Concrete Pavements. Article in Transportation Research Record Journal of the Transportation Research Board Transportation Research Record Journal of the Transportation Research Board, no. 2629:24-32. https://doi.org/10.3141/2629-05.

16. Farnam, Y., Zhang, B., and Weiss, J. (2017). Evaluating the Use of Supplementary Cementitious Materials to Mitigate Damage in Cementitious Materials Exposed to Calcium Chloride Deicing Salt. Cement and Concrete Composites 81:77-86. https://doi.org/10.1016/j.cemconcomp.2017.05.003.

17. Whatley, S.N., Suraneni, P., Azad, V.J., Isgor, O.B., and Weiss, J. (2017). Mitigation of Calcium Oxychloride Formation in Cement Pastes Using Undensified Silica Fume. Journal of Materials in Civil

https://doi.org/10.1061/(ASCE)MT.19435533.0002052.

18. Suraneni, P., Monical, J., Unal, E., Farnam, Y., and Weiss, J. (2017). Calcium Oxychloride Formation Potential in Cementitious Pastes Exposed to Blends of Deicing Salt. ACI Materials Journal. 114(4):63141. https://doi.org/10.14359/51689607.

19. Thomas, M.D.A., Hooton, R.D., Scott, A., and Zibara, H. (2012). The Effect of Supplementary 
Cementitious Materials on Chloride Binding in Hardened Cement Paste. Cement and Concrete Research. https://doi.org/10.1016/j.cemconres.2011.01.001.

20. Weiss, W.J., Suraneni, P., Azad, V.J., and Isgor, O.B. (2016). Calcium Oxychloride Formation in Pastes Containing Supplementary Cementitious Materials: Thoughts on the Role of Cement and SuppleMentary Cementitious Materials Reactivity. RILEM Technical Letters. 1(0):24. https://doi.org/10.21809/rilemtechlett.2016.7.

21. Monical, J., Unal, E., Barrett, T., Farnam, Y., and Weiss, W.J. (2016). Reducing Joint Damage in Concrete Pavements. Transportation Research Record: Journal of the Transportation Research Board 2577 (January). Transportation Research Board of the National Academies:17-24. https://doi.org/10.3141/2577-03.

22. Farnam, Y., Dick, S., Wiese, A., Davis, J., Bentz, D., and Weiss, J. (2015). The Influence of Calcium Chloride Deicing Salt on Phase Changes and Damage Development in Cementitious Materials. Cement \& Concrete Composites 64:1-15. https://doi.org/10.1016/j.cemconcomp.2015.09.006.

23. Monical, J., Villani, C., Farnam, Y., Unal, E., and Weiss, W.J. (2016). Using Low-Temperature Differential Scanning Calorimetry to Quantify Calcium Oxychloride Formation for Cementitious Materials in the Presence of Calcium Chloride. Advances in Civil Engineering Materials 5(2):20150024. https://doi.org/10.1520/ACEM20150024.

24. Han, B., Choi, J.H., Dantzig, J., and Bischof, J.C. (2006). A Quantitative Analysis on Latent Heat of an Aqueous Binary Mixture. Cryobiology. 52(1):146151. https://doi.org/10.1016/j.cryobiol.2005.09.007.

25. Langan, B.W., Weng, K., and Ward, M.A. (2002). Effect of Silica Fume and Fly Ash on Heat of Hydration of Portland Cement. Cement and Concrete Research. https://doi.org/10.1016/S00088846(02)00742-1.

26. M. Balapour, A. Joshaghani, F. Althoey, Nano-SiO2 contribution to mechanical, durability, fresh and microstructural characteristics of concrete: A review, Constr. Build. Mater. 181 (2018). doi:10.1016/j.conbuildmat.2018.05.266.

27. Cheng-yi, H., and Feldman, R.F. (1985). Hydration Reactions in Portland Cement-Silica Fume Blends. Cement and Concrete Research. https://doi.org/10.1016/0008-8846(85)90056-0.

28. Roy, D., Skalny, J., and Diamond, S. (1982). Effects of Blending Materials on the Rheology of Cement Pastes and Concretes. In Symposium M, Concrete Rheology, Materials Research Society, 152-73. PA.

29. McCarthy, G.J., and Thedchanamoorthy, A. (1988). Semi-Quantitative X-Ray Diffraction Analysis of Fly Ash by the Reference Intensity Ratio Method. MRS Proceedings 136 (January). Cambridge University Press:67. https://doi.org/10.1557/PROC-136-67.

30. McCarthy, G.J., Swanson, K.D., Keller, L.P., and Blatter, W.C. (1984). Mineralogy of Western Fly Ash. Cement and Concrete Research. 14(4).
Pergamon:471-78. https://doi.org/10.1016/00088846(84)90121-2.

31. Roy, D.M., Luke, K., and Diamond, S. (1984). Characterization of Fly Ash and Its Reactions in Concrete. MRS Proceedings 43 (January). Cambridge University Press:3. https://doi.org/10.1557/PROC-433.

32. Diamond, S. (1983). On The Glass Present In LowCalcium And In High-Calcium Flyashes. CEMENT and CONCRETE RESEARCH. 13:459-464.

33. Tishmack, J.K., Olek, J., and Diamond, S. (1999). Characterization of High-Calcium Fly Ashes and Their Potential Influence on Ettringite Formation in Cementitious Systems. Cement, Concrete and Aggregates. https://doi.org/10.1520/CCA10512J.

34. Gebler, S.H., and Klieger, P. (1986). Effect of Fly Ash on Physical Properties of Concrete. Special Publication. 91(February): 1-50. https://doi.org/10.14359/10063.

35. Johnston, C. (1994). Deicer Salt Scaling Resistance and Chloride Permeability. Concrete International. 16(8):48-55.

36. Bortz, B.S. (2010). Salt-Scaling Durability of Fly Ash Concrete. Kansas State University. http://krex.kstate.edu/dspace/handle/2097/3878.

37. Valenza, J.J., and Scherer, G.W. (2006). Mechanism for Salt Scaling. Journal of the American Ceramic Society. 89(4):1161-79. https://doi.org/10.1111/j.1551-2916.2006.00913.x.

38. Dean, S.W., Naik, T.R., Kraus, R.N., Ramme, B.W., and Y-M Chun. (2005). Decing Salt-Scaling Resistance: Laboratory and Field Evaluation of Concrete Containing up to $70 \%$ Class C and Class F Fly Ash. Journal of ASTM International. 2(7):11912. https://doi.org/10.1520/JAI11912. 